RECIIS - R. Eletr. de Com. Inf. Inov. Saúde. Rio de Janeiro, v.6, n.2, Sup., Ago., 2012

[www.reciis.icict.fiocruz.br] e-ISSN 1981-6278

* Novas escrituras e mediações em saúde

\title{
A experiência do observatório baiano de regionalização: uma ferramenta para avaliação e qualificação da gestão regionalizada do SUS na Bahia
}

\author{
Mariana Bertol Leal \\ Leal, M.B. - FSP/USP \\ Estevão Rodrigues Toffoli \\ Toffoli, E.R. - SESAB \\ Lidiane Souza \\ Souza, L. - SESAB \\ Maria Conceição Benigno Magalhães \\ Magalhães, M.C.B. - SESAB \\ Pedro José Freire Castro \\ Castro, P.J.F. - SESAB \\ Silvio Roberto Medina \\ Medina, S.R. - SESAB \\ DOI: $10.3395 /$ reciis.v6i2.Sup1.628pt
}

No Estado da Bahia, desde 2007, iniciou-se a construção do novo Plano Diretor de Regionalização (PDR) que definiu o território das 9 macrorregiões e das 28 microrregiões de saúde. A partir desse novo arranjo regional, e considerando o preconizado pela Portaria no 399/GM de 22 de fevereiro de 200, que institui o Pacto pela Saúde 2006, foram instituídas as instâncias regionais de pactuação, os Colegiados de Gestão Microrregional (CGMR) em todas as 28 microrregiões. Ainda, como inciativa da gestão estadual, foi construído, com ampla participação das diversas áreas técnicas e diretorias regionais de saúde, o novo Plano Estadual de Saúde (PES) o qual considerou, desde sua concepção, um processo de planejamento das ações de saúde de forma regionalizada.

Esse cenário exigiu, da equipe técnico-política da Secretaria Estadual de Saúde da Bahia (SESAB), uma certa capacidade de articulação do conjunto de ações de saúde que foram planejadas regionalmente. A intenção era de efetivar os processos de planejamento e tornar as regiões de saúde eficientes e resolutivas, potencializando esses arranjos das regiões de saúde apesar de existirem, ainda, grandes vazios assistenciais.

A intenção foi de fortalecer o Pacto pela Saúde e a regionalização do SUS a partir de um processo de construção de pactos entre os gestores que expressassem os compromissos e as responsabilidades dos diferentes gestores e de seus territórios para a viabilização do desenho das redes regionalizadas de saúde. Buscou-se fortalecer as unidades com maior resolutividade nas redes, sendo que os serviços com maior capacidade de resolutividade estão localizados nos pólos de micro e macrorregiões e, portanto, potencializou-se os municípios que são pólos 
regionais. Da mesma forma, buscou-se planejar e programar as ações e serviços de saúde a partir da nova Programação Pactuada Integrada (PPI) considerando a realidade da capacidade instalada de serviços e o fluxo de acesso dos usuários. Isso possibilitou repensar a lógica da programação, valorizando o processo de contratualização, o que amplia o escopo de uma programação baseada somente no histórico da produção. Assim, foi possível planejar um processo de substituição progressiva na lógica da programação em saúde.

A atual PPI, iniciada em 2008, teve sua aprovação na CIB de maio de 2010 (Resolução 141anexo XI), após um longo processo de construção coletiva e participativa dos parâmetros e critérios, envolvendo as diversas áreas técnicas, COSEMS e MS, bem como os 417 municípios que tiveram seus compromissos pactuados e assumidos nos 28 CGMR.

O papel dos CGMR, que foram centrais na construção da PPI, ainda deve ser melhor valorizado especialmente pela sua importante participação nesse processo de avaliação e qualificação que efetivará a PPI Viva. Através dos CGMR pretende-se garantir de forma mais qualificada, democrática e descentralizada, a revisão dos pactos, bem como seu acompanhamento e monitoramento.

Assim, o processo de avaliação da PPI está garantindo um processo solidário e participativo que assegura novos pactos para adequação e qualificação, assegurando uma programação ao conjunto dos municípios que dialogue com as necessidades da população, considerando os fluxos regulatórios e os mecanismos de acesso nos diversos serviços. Nesse sentido, o GT PPI está com a responsabilidade de formular um conjunto de ações de qualificação da programação enquanto um mecanismo permanente de repactuação para que a dinâmica de organização da rede e dos serviços seja absorvida também pelo processo de planejamento e programação assistencial.

Com esse cenário, a PPI se constituiu como um instrumento de planejamento no SUS, onde é possível integrar a lógica da regionalização e do desenho das redes de atenção à própria programação. No processo desenvolvido para a construção da PPI 2010, priorizou-se espaços democráticos enfocando nessa construção as características da gestão estratégica e participativa. Assim, pode-se dizer que o processo desenvolvido se configurou num processo dinâmico de planejamento e programação, buscou se integrar com as diversas ferramentas já existentes e com as políticas em desenvolvimento, especificamente os planos de saúde e os dados e indicadores de saúde foram ferramentas essenciais utilizadas ao longo desse processo.

Da mesma forma, o papel dos Colegiados de Gestão Microrregional (CGMR) foi fundamental nesse processo de construção, tanto para a configuração do processo participativo e democrático, quanto para a legitimação do processo com o conjunto dos gestores municipais. As rodadas micro e macrorregionais de programação foram todas realizadas nos espaços dos colegiados, o que apoiou tanto no fortalecimento dos próprios colegiados como instâncias de governança regional como também na legitimação da construção da PPI como processo participativo e vivo. Isso pois durante todo o processo da PPI como também ao final dela, foi pactuado com o conjunto de gestores a metodologia da PPI viva, isso foi um dos grandes objetos dessa experiência do Observatório Baiano de Regionalização do SUS na Bahia.

Nesse sentido, compreendendo que um amplo processo de fortalecimento e qualificação da gestão está em desenvolvimento, para intensificar os processos de avaliação, monitoramento, regulação, cooperação e controle, essenciais para a qualificação da gestão regionalizada do 
SUS e implantação das linhas de cuidado, foi implantado o projeto do Observatório Baiano de Regionalização do SUS, o qual vêm sendo progressivamente adequado e qualificado.

Esse projeto do Observatório foi planejado inicialmente para apoiar o processo da PPI viva, seria um mecanismo de ajudar a tornar mais vivo o processo de planejamento e programação, dando mais transparência, no entanto, ao longo do tempo, foi incrementado com várias funcionalidades que tornaram a ferramenta interessante a todo o processo de regionalização.

Para entendermos uma pouco mais, é importante definir a PPI como um processo instituído no âmbito do SUS, onde, em consonância com o processo de planejamento, são definidas e quantificadas as ações de saúde para população residente em cada território, bem como efetuados os pactos intergestores para garantia de acesso da população aos serviços de saúde. Ela é um instrumento para alocação de recursos financeiros, especialmente os de média e alta complexidade que não têm bloco de financiamento específico para os municípios. O recurso que é planejado e programado é o teto financeiro de média e alta complexidade (MAC), o qual deve ser definido a partir do planejamento regionalizado das ações e serviços de saúde (REGIONALIZAÇÃO) através da ferramenta da PPI a qual somente se viabilizará a partir dos pactos de gestão (PACTO e TRS) e dos processos regulatórios (REGULAÇÃO).

Esse processo de planejamento e programação, vinculado a um intenso processo de estímulo à regionalização do SUS, tornou-se um motivo importante para o desenvolvimento do projeto do Observatório. O objetivo do Observatório Baiano de Regionalização do SUS foi de desenvolver e implantar uma nova tecnologia da gestão regionalizada que permitisse o acompanhamento e desenvolvimento dos CGMR, do PDR e da Programação Pactuada Integrada (PPI). Para isso, foi construído para operar com o conceito de um "conjunto de soluções tecnológicas e operacionais que abrangem a produção, tratamento, análise, disseminação e usos de informações e conhecimentos sobre aspectos administrativos, técnicos e políticoorganizacionais dos sistemas municipais, microrregionais, macrorregionais e estadual de saúde da Bahia visando a produção de evidências sobre estrutura, processo e resultados com o objetivo de subsidiar os gestores em diversos âmbitos para a tomada de decisões".

Os objetivos específicos do projeto foram:

- Caminhar junto e Fortalecer o processo de Regionalização do SUS-Bahia e implantação do Pacto pela Saúde, tanto do ponto de vista da gestão desse processo através dos Colegiados de Gestão Microrregional até a construção e organização concreta dos Sistemas Regionais de Saúde.

- Apoiar os municípios e as DIRES (no apoio aos municípios) na qualificação dos sistemas de informação relacionados com a gestão descentralizada e regionalizada e gestão da rede de atenção especializada tais como o SISPACTO, SISPPI, SISREG, SCNES, SIA e $\mathrm{SIH}$;

- Apoiar o processo de produção de indicadores para os componentes do sistema de acompanhamento e avaliação da PPI de forma facilitada a partir de descentralização do sistema informatizado específico (SIS PPI) e pela formação de apoiadores do processo em cada microrregião; 
- Apoiar o processo de mediação das pactuações necessárias coerentes com as modelagens das linhas de cuidado em âmbito regional, dando a dinâmica necessária à PPI e aos processos de contratualização;

- Dar condições técnicas e informações suficientes para apoiar os municípios e DIRES nos processos de chamamentos públicos, credenciamento e recredenciamento, regulação, controle e avaliação dos serviços de saúde;

- Produzir inteligência para a gestão a partir do cotidiano dos serviços e dos sistemas de saúde e, assim, fomentar a incorporação efetiva dos serviços nas redes de gestão descentralizada;

- Apoiar para avançar numa Política de Educação Permanente coerente com a mudança do processo de trabalho do cuidado e da gestão, com o envolvimento e integração dos gestores, prestadores de serviços e trabalhadores e com a constituição de Redes MicroRegionais de Educação Permanente, garantindo mais autonomia e capacidade para os municípios e DIRES articulados nas mesmas;

- Articular os Serviços em Sistemas Regionais de Saúde que busquem garantir o cuidado integral com prioridade de estruturação de Redes relacionadas às Linhas de Cuidado definidas como prioritárias pela SESAB;

- Qualificar a própria capacidade de gestão da PPI, alocando a este importante instrumento da gestão, maior vitalidade e maior poder de induzir a inovações tecnoassistenciais no sistema estadual de saúde da Bahia.

Essa proposta se consituiu como importante ferramenta para apoiar o processo de avaliação em saúde a partir da compreensão de que devem ser organizados sistemas regionalizados de saúde. O Observatório é um dispositivo potencialmente articulador das diversas ações segmentadas hoje desenvolvidas no âmbito da Secretaria de Saúde do Estado da Bahia e tem como eixos de seu trabalho: Eixo I - Modelagem das Linhas de Cuidado; Eixo II - Lógica de Programação do cuidado e Alocação de Recursos; e, Eixo III - Contratualização, Regulação, Avaliação, Controle e Acompanhamento. Ele pretende suprir a lacuna do monitoramento e da avaliação, com enfoque na atual política de saúde. Sua implantação está ocorrendo de forma ascendente, iniciando-se em unidades sentinela e nos CGMR já que o monitoramento dos fluxos assistenciais e identificação de evidências de problemas devem ser apontados a partir da ponta. Dessa forma, estão sendo implementadas Estações Microrregionais com bases sentinelas e uma Estação Estadual para a sistematização das informações.

As estações microrregionais devem ser compostas por bases sentinela que são serviços de referência para a coleta de informações estratégicas e o monitoramento de fluxos e eventos assistenciais marcadores do desempenho da gestão municipal e microrregional. Elas devem estar organizadas a partir de um componente operacional que foi proposto com o objetivo de viabilizar a organização de relatórios trimestrais de informações e registro sobre organização da gestão e da atenção e desempenho dos sistemas microrregionais de saúde e a análise dos Colegiados Microrregionais, com apoio das DIRES e dos apoiadores do nível central da SESAB. Da mesma forma, considerava-se que o componente técnico-político dessas estações seriam os Colegiados Microrregionais, que tem a responsabilidade de analisarem os relatórios 
(Câmaras Técnicas), produzindo conhecimento útil à gestão, ajudando no desenho de estratégias de intervenção e encaminhando a proposta à estação estadual do Observatório.

A estrutura da estação estadual foi estruturada com um base estadual, responsável pela sistematização e pré-análise das informações e conhecimentos em recortes macrorregionais e estadual e submissão de relatório trimestral da gestão regionalizada à decisão da SESAB e CIB. Possibilita o subsídio para a tomada de decisão da Regionalização Viva! Essa estação estadual está vinculada à Diretoria de Programação e Desenvolvimento Regional da SESAB (Apoio Institucional e Matricial) e mantida com a participação de apoiadores das diversas Superintendências, DIRES e Membros Efetivos dos CGMR das diversas áreas técnicas.

Logo após da aprovação da PPI em maio de 2010, após 18 meses de intenso trabalho nas diversas regiões e envolvendo todos os gestores municipais da Bahia, foi organizada a primeira funcionalidade da ferramenta virtual. Essa funcionalidade apresenta a própria programação de forma organizada e transparente, deixando explícitos o conjunto de pactos firmados nas diversas regiões e municípios para assegurarem o acesso. Dessa forma, ficou fácil saber como deveriam ocorrer os encaminhamentos e o processo regulatório no SUS.

A partir da nova PPI e da própria ferramenta do Observatório criada, muitos municípios começaram a colocar barreira no acesso embasados no programação feita, isso levou a necessidade de novos pactos o que afirmou a necessidade da PPI viva. Desde novembro de 2010, foi constituído um grupo de trabalho ligado à Comissão Intergestores Bipartite (CIB) para trabalhar o conjunto de alterações na PPI. Até o momento, mais de 30 alterações e realocações já foram feitas e aprovadas em CIB resultando em alterações nos tetos financeiros dos municípios. Muito disso foi possível por causa da ferramenta do Observatório.

A partir da publicação do Decreto no 7.508, de 28 de junho de 2011, que regulamenta a Lei no 8.080, algumas mudanças no processo organizativo do SUS são trazidas para o cotidiano da gestão. Nessa perspectiva, a PPI agora ganha um novo status frente ao processo de planejamento e gestão regionalizada pois agora deverá abranger o conjunto de ações e serviços de saúde e não somente a média e alta complexidade cuja fonte de financiamento é federal.

A PPI tem por objetivo organizar a rede de serviços, dando transparência aos fluxos estabelecidos e definir, a partir de critérios e parâmetros pactuados, os limites financeiros destinados à assistência da população própria e das referências recebidas de outros municípios.

Nessa perspectiva, os novos conceitos trazidos pelo Decreto serão incorporados gradualmente à estrutura organizativa do sistema de saúde. Através do desenvolvimento de um planejamento participativo e regionalizado será definido um Mapa de saúde para cada região e que deverá ser subsídio para o desenho das redes de atenção de forma articulada com as políticas prioritárias e aproveitando a oportunidade de reorganizar os serviços a partir da construção de uma programação das ações e serviços de saúde. Essa programação, que poderá ser construída a partir do acúmulo já existente da construção da PPI, deverá contemplar o conjunto de ações e serviços de saúde de cada região a partir da definição do desenho das redes, embasado na construção de um planejamento regionalizado e integrado. Assim, não serão mais programados somente os serviços de média e alta complexidade a partir de agora, essa nova programação será mais ampla para todo o sistema pois resultará 
num anexo importante do Contrato Organizativo de Ação Pública - COAP, atrelado às metas pactuadas em cada território e região.

Ou seja, a partir dessa nova proposta de organização do SUS, o que deve ser ofertado em termos de ações e serviços individuais e coletivos será definido a partir da RENASES e da RENAME resultando numa programação geral que deverá contemplar a quantidade e a especificação de cada ação e serviço a ser ofertado em cada território de acordo com a conformação das redes de atenção e atrelando a programação financeira e pactuação entre os gestores.

Ou seja, a nova PPI será mais abrangente, terá um papel mais estratégico no planejamento dos sistemas de saúde regionalizados organizados a partir da constituição das redes de atenção à saúde e deverão contemplar o conjunto de fontes de financiamento que sustentam o funcionamento do SUS, trazendo mais transparência nos três níveis de gestão do SUS e como estão sendo aplicados os recursos da saúde.

Assim, esse processo organizativo deverá resultar na formalização dos pactos entres os gestores e na assinatura dos COAP que definirão responsabilidades e compromissos entre as partes envolvidas para efetivação do SUS em cada território. Esse objetivo deverá ser monitorado e avaliado por um processo de contratualização que terá permanente avaliação a partir de processos que estão sendo disparados para qualificação do acesso e atenção, pelo Programa de Avaliação para Qualificação do SUS através do índice de desempenho do SUS, bem como pelo Programa de Melhoria do Acesso e da Qualidade da Atenção Básica.

Essas propostas pretendem apoiar o processo de qualificação do SUS, dar fôlego para o processo de planejamento regionalizado a partir da definição dos desenhos de redes e, dessa forma, promover uma constante e gradual melhoria da programação em saúde, como forma de fortalecer uma gestão democrática, solidária e efetiva do SUS-BA, e possibilitar uma melhora na qualidade de vida da população.

Nessa perspectiva é fundamental a qualificação dos processos de avaliação do SUS. Assim, o projeto que já vem sendo desenvolvido do Observatório Baiano de Regionalização do SUS ganha potência pois busca apoiar esse processo de avaliação. Hoje ele já é uma ferramenta importante para o monitoramento da PPI e do funcionamento dos antes chamados CGMR e das, agora, chamadas Comissões Instergestoras Regionais (CIR).

A ferramenta do Observatório recentemente habilitou um mecanismo de acompanhamento das CIR on line, organizando o processos de trabalho das mesmas e potencializando a avaliação do processo de governança regional do SUS na Bahia. Essa funcionalidade ajuda no monitoramento do que têm sido trabalhado, debatido e decidido nas diversas regions de saúde, ajuda nos processo de registro e documentação, atribui valor ao processo regional e descentralizado e potencializa as instâncias regionais no processo de governance, assegurando potência ao processo decisório regional.

Outra funcionalidade da ferramenta será disponibilizada pela internet em breve possibilitando a avaliação da PPI e do processo de acesso e regulação nas diversas regiões e diversos municípios baianos. Essa funcionalidade que está sendo desenvolvida permite o cruzamento das informações da programação com a produção apresentada e aprovada e pode apoiar o processo de adequação da PPI e da regulação bem como pode servir de espaço privilegiado de 
reorganização do acesso ao SUS. Espera-se que essa funcionalidade auxilie no trabalho do grupo de trabalho da PPI dando subsídio às análises realizadas para realocação de recursos.

Essa aposta possibilita o subsídio para a tomada de decisão da Regionalização Viva! Essa ferramenta foi desenvolvida para ajudar avaliação do planejamento e execução das políticas de saúde bem como para qualificar a gestão no processo de tomada de decisão, aproximando os gestores de um conjunto de informações necessárias e estratégicas para uma avaliação mais crítica sobre os caminhos a serem seguidos. Assim, o Observatório pretende servir como ferramenta de gestão potente para apoiar os processos de descentralização e regionalização do SUS na Bahia bem como para acompanhar e avaliar o processo desencadeado para reorganização dos sistemas regionalizados de saúde baseados no PDR e na atual política estadual que prioriza a regionalização com apoio no funcionamento das CIR nas diversas regiões do estado. 